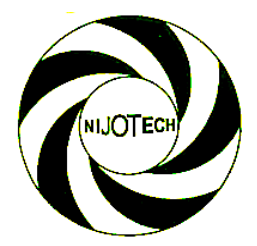

Nigerian Journal of Technology (NIJOTECH)

Vol. 38, No. 3, July 2019, pp. $\mathbf{7 9 8} \mathbf{- 8 0 3}$

Copyright@ Faculty of Engineering, University of Nigeria, Nsukka,

Print ISSN: 0331-8443, Electronic ISSN: 2467-8821

wWw.nijotech.com

http://dx.doi.org/10.4314/njt.v38i3.36

\title{
AN INVESTIGATION ON THE EXTENT OF SOIL POLLUTION RESULTING FROM VEHICULAR EMISSION
}

\author{
J. C. Osuagwu ${ }^{1, *}$, J. C. Agunwamba² and S. A. Okoli ${ }^{3}$ \\ 1, Department of Civil Engineering, Federal University of TeChnology, OWerri, Imo State, Nigeria \\ 2,3, Department of Civil Engineering, University of Nigeria, NSUKKA. ENUGu State. NIGERIA \\ E-mail addresses: ${ }^{1}$ engrjcosuagwu@yahoo.com, ${ }^{2}$ jonah.agunwamba@unn.edu.ng, \\ 3 appoloniasure@yahoo.com
}

\begin{abstract}
Vehicular emissions have been found to constitute the major source of environmental pollution. Unfortunately, it has been observed that in most developing countries like Nigeria, the contribution of vehicular emission to soil pollution and its implication on the environment is yet to be understood. This study focused on estimating the extent of soil pollution resulting from vehicular emission. Since the most serious effect of pollution with regard to heavy metals is associated with Lead, therefore it was considered as the key element in the investigations. Three locations within Nsukka including a motor Park (A), a primary school (B) and a location off town (C) with little or no traffic were chosen for collection of soil samples. A total of 63 samples were collected from the 3 sampling point sover a 3month period. The method of analysis used for determination of lead concentration was the calorimetric - sulphide method. This involved the use of chemicals and a spectrometer to determine the amount of lead (ppm) present in a given soil sample. Analysis of the results indicated higher level of Lead concentration at locations exposed to relatively higher levels of vehicular emission. Samples from location A had highest levels of Lead concentration (max = $3.7 \mathrm{ppm}$ ) followed by location $B$ ( $\max =0.86 \mathrm{ppm})$. Interestingly, Samples from location $C$ which is not exposed to vehicular traffic consistently had zero level of Lead concentration. Results of the studies did not indicate any correlation between Lead concentration and recorded rainfall amounts. Considering the health hazards that could result from vehicular soil pollution there is need for the establishment of comprehensive monitoring system and information gathering on pollution levels in our environment, including soil. The use of leaded petrol should be regulated.
\end{abstract}

Keywords: Vehicular Emission, soil pollution, Lead concentration.

\section{INTRODUTION}

The increase in global population, mechanization and the rising demand for the transportation of goods and services have resulted in the increase of the number of vehicle that operate in many cities of the country. A major effect of this trend is the issue of environmental pollution.

The use of motor vehicles as a major means of transportation has resulted in several environmental, economic and social problems to the society. Over 600 million people globally are exposed to hazardous level of traffic generated pollutants [1]. Following the internal combustion engine during the early decades of the last century, there was growing demand for petrol of higher octane rating to avoid unseen combination in the engine cylinder generally known as " knocking ".

In the early 1920 's, it was discovered that the addition of lead alkyls (tetra ethyl and tetra methyl lead) to petrol helps to overcome this problem. As time went on, the use of leaded petrol rapidly became a standard practice. As the combustion of fuel takes place in the engine of motor vehicles a lot of pollution are released from the exhaust into the environment. The emission

* Corresponding author, tel: +234-803-331-4726 
of lead and other toxic pollution by vehicles has been found to depend on a number of factors such as the type of fuel used, the type and age of vehicle, the type of exhaust used by the vehicle, the vehicle speed and its loading condition. Most of these pollutants are harmful to both human and animal health and phytotoxic to plants and thus can reduce agricultural productivity. As these substances are released, some get entrapped into the surrounding soil while some can travel several kilometers into the air thus leading to both air and soil pollutions. Some of them during rain can percolate or be washed into stream leading to both ground water and surface water pollution.

Soil pollution occurs when contaminants that lead to change in the physical or chemical properties of the soil are introduced in the soil. The solid components of soil are usually clustered together in form of aggregates, thus creating a system of interconnected voids of various sizes filled with either air or water. These voids facilitate the accumulation of substances that settle on them easily thus resulting to pollution. Soils are dynamic bodies in equilibrium with environmental forces acting upon them[2]. Based on this, they are subjected to short term fluctuation such as variation in moisture content, $\mathrm{pH}$ and redox condition thus undergoing gradual alteration in their physical and chemical properties due to change in management and environmental factors.

Soil is an extremely complex medium and different fractions and constituents have variable degree of reactivity to introduced components. Soil pollution may lead to acidic conditions which promote a range of reactions including the production of hydrogen cyanide from sulphides in the presence of moisture, increase in the attack to building materials and services [3]. Environmental pollution is a product of urbanization, technology and other factors that result from population density, mechanization and industrialization that serve to provide the necessities of the population. In the urban areas, the major sources of pollution are anthropogenic. On the other hand contamination from natural sources predominate the rural areas.

In most developing countries of the World, vehicular growth has not been checked properly by Environmental regulating agencies leading to increase in levels of pollution[4].Traffic emissions contribute about $50-80 \%$ of $\mathrm{NO}_{2}$ and $\mathrm{CO}$ concentration in developing countries[5,6]. Studies and aerial view of Nigeria have shown that our atmosphere is highly polluted. This is very evident in the number of smoky vehicles plying our roads on daily basis, causing visibility problems and sometimes accidents[7]. In Nigeria much attention is given on general Industrial pollution in oil Industries, with little reference on damage from pollution caused by mobile transportation [8].

Vehicular emission is at its peak when there is an increase in population, together with increase in number of vehicles on roads [9]. The emission of lead and other toxic substances have diverse impact on the environment. Some of the major impact of soil pollution on various aspects of human environment which are of permanent interest are associated with the public health, water quality, agricultural productivity and the engineering properties of soil.

The effect of pollutants may be instantaneous while others may take years to manifest. Similarly some health hazards caused by exposure to polluted soil may be cured easily while some have a long term effect on the victim. For instance, in single exposure studies in adults, Lead has a half-life time in blood of approximately 25 days, about in soft tissues and more than 25 days in non-liable portion of bone. A person's Lead blood level can take several months or sometimes years to drop significantly even after complete removal from the source of pollution [10]. Several health hazards are associated with exposure to polluted soil. Children are most vulnerable as they usually play with soil. Various studies have shown that heavy metals such as $\mathrm{Pb}, \mathrm{Cd}, \mathrm{Ni}$, amongst others are responsible for certain diseases that have lethal effects on man and animal and due to their accumulation and long term retention by plants and animals, these metals are very dangerous [11].

Though there are many pollutants that can result from vehicular emission, only lead was analyzed in this study. Lead is an insidious and slow reacting poison that is easily absorbed and remains in the body. It is especially toxic to children and young of other species $[12,13]$. Most of the lead particles deposited on soil are retained and eventually become mixed into the surface layer (or deeper in the case of cultivated soil). Soil is contaminated by Lead from various sources such as flaking paint, incinerators, and motor vehicles that use leaded gasoline.

Considering the diversity of problems which can arise from soil pollution this study is aimed at evaluating the concentration of pollutants on soils as a result of vehicular emission in the study area. 


\section{MATERIALS AND METHODS:}

The study area was Nsukka located in Enugu state south eastern Nigeria (Fig 1).The area lies between Latitude $6^{\circ} 35^{\prime}-6^{\circ} 55^{\prime}$ North and Longitude $7^{\circ} 10^{\prime}-7^{\circ} 35^{\prime}$ East.

Since the most serious effect of pollution with regard to heavy metals is associated with Lead, therefore it was considered as the key element in the investigations. Soil samples were collected and tested experimentally in the laboratory to obtain data used for analysis.

The study area is Nsukkametropolis and 3sampling locations were chosen.

(i) Nsukka (A) old park which is the terminal point for different types of vehicles including old and new cars and buses at different maintenance conditions.

(ii) At a primary school in Enugu road (B) which is exposed to heavy traffic along the road and vehicles that park in the school playing ground.

(iii) Odenigwe Nsukka (C) located some distance away from the town. Samples were collected from the interior part of the community where there is virtually no traffic. It was assumed that there was no pollution from other sources.

The samples were collected twice a week for a period of 3 months. Thus a total of 63 samples were collected from the 3 sampling points.
The method of analysis used for determination of lead concentration in the samples was the calorimetric sulphide method. This involved the use of chemicals and a spectrometer to determine the amount of lead (ppm) present in a given soil sample.

After obtaining the optical density from the samples, the amount of lead (ppm) present in each sample was calculated using the relation:

Amount of Lead (ppm)

$$
=O D \times G F \times \frac{\text { Extract }}{\text { Aliquot }} \times \frac{1}{W}
$$

Where;

$\mathrm{OD}=$ Absorption or the optical density of the sample.

$\mathrm{GF}=$ Graph factor of $\mathrm{Pb}$ calculated previously from a standard solution of $\mathrm{Pb}$

Aliquot $=$ Volume of part of the sample extract used (10ml in this case)

$\mathrm{W}=$ weight of sample $(\mathrm{g})$ before extraction.

For the total Lead content, the amount of Lead present was calculated as follows;

Amount of Lead (ppm)

$$
=\left(O D \times G F \times \frac{\text { Extract }}{\text { Aliquot }} \times \frac{1}{W}\right) D F
$$

Where DF $=$ Dilution factor which the ratio of the volume of the extract to the volume of distilled water used in diluting the extract.

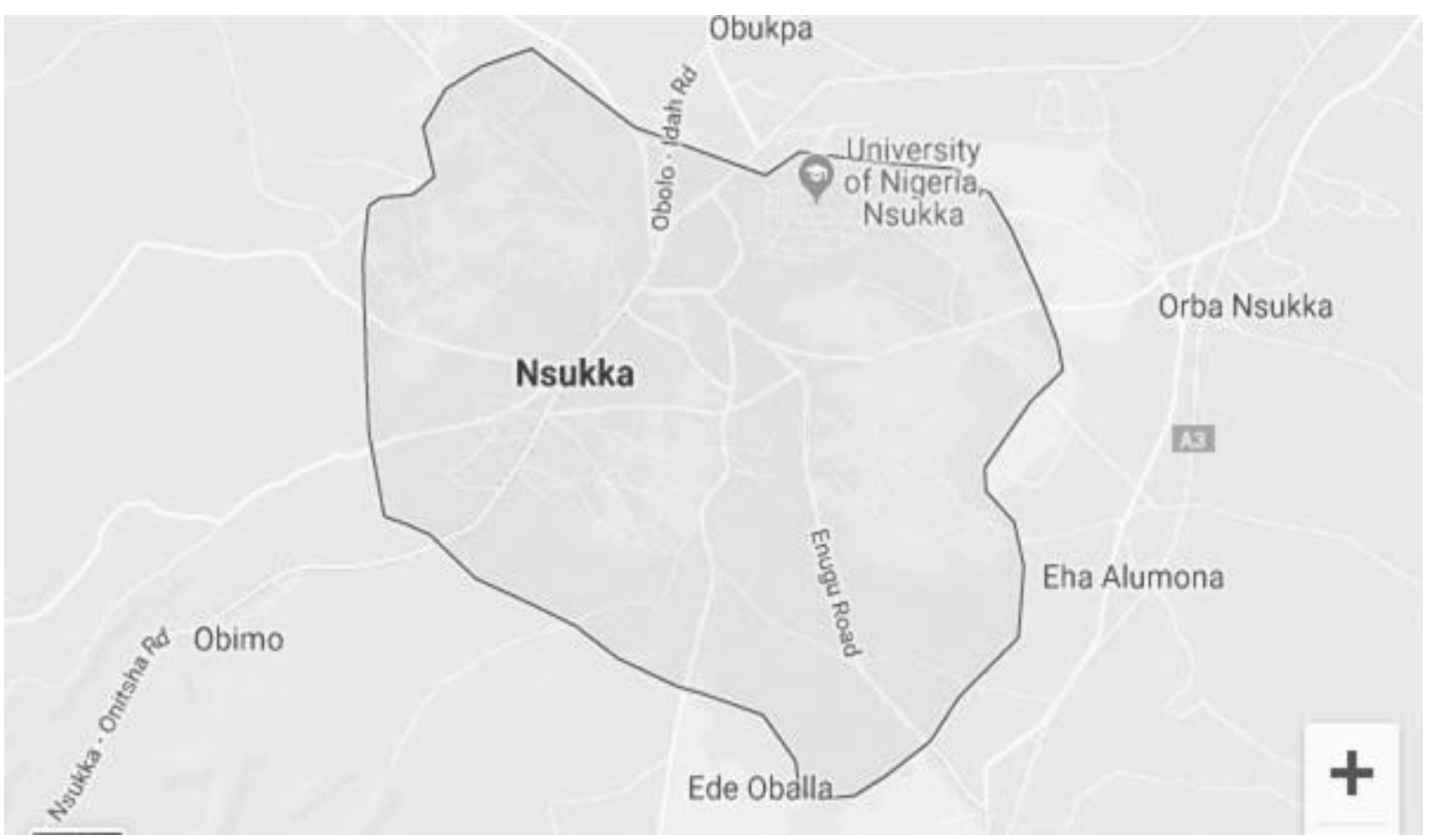

Figure 1: Project area

Source: [14] 


\section{RESULTS AND DISCUSSIONS}

Plots of Lead concentration against time for the 3 months of March-May are presented in Figures 2-4. Generally, there was a fluctuation on the level of Lead concentration for the various days.

At location A (month of March), higher concentrations were recorded on early days of the week. This could be attributed to higher volume of traffic during such times. For location B, the graph indicates slight concentration of lead on the $1^{\text {st }}$ and $6^{\text {th }}$ days of the week while zero concentrations were recorded for the other days. This may be as a result of vehicles being parked at the point of collection. On the other hand, a certain quantity of Lead might had been emitted prior to those days but was slight enough to be swept off before subsequent collections within 2 weeks interval. For location C, there is constant absence of Lead. This could be as a result of lack of traffic or other sources of pollution at the location.
For the month of April, the same trend of fluctuation continued at locations A and B. However the effect of rainfall may have contributed to higher levels of concentration days after rainfall. This is attributable to increase in absorption of pollutant by soil of higher moisture condition. On the other hand, samples collected on rainfall days indicated reduction in Lead concentration. This is as a result of leaching and percolation of pollutants from the surface as a result of the rainfall.

For the month of May, there was zero level of Lead concentration throughout the collection period at location $C$. The same phenomenon was recorded forthe months of March and April.

A study on Vehicular pollution of roadside soils in Ota, Ogun state Nigeria recorded Lead concentrations as high as $25 \mathrm{mg} / \mathrm{l}$ [16].Consistent with the results of this study, the high concentrations of lead could be attributed to Lead particles from gasoline combustion which consequently settles on roadside soils..

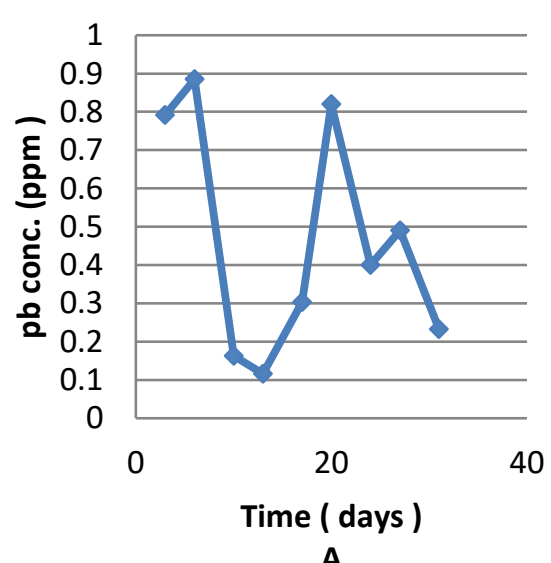

A
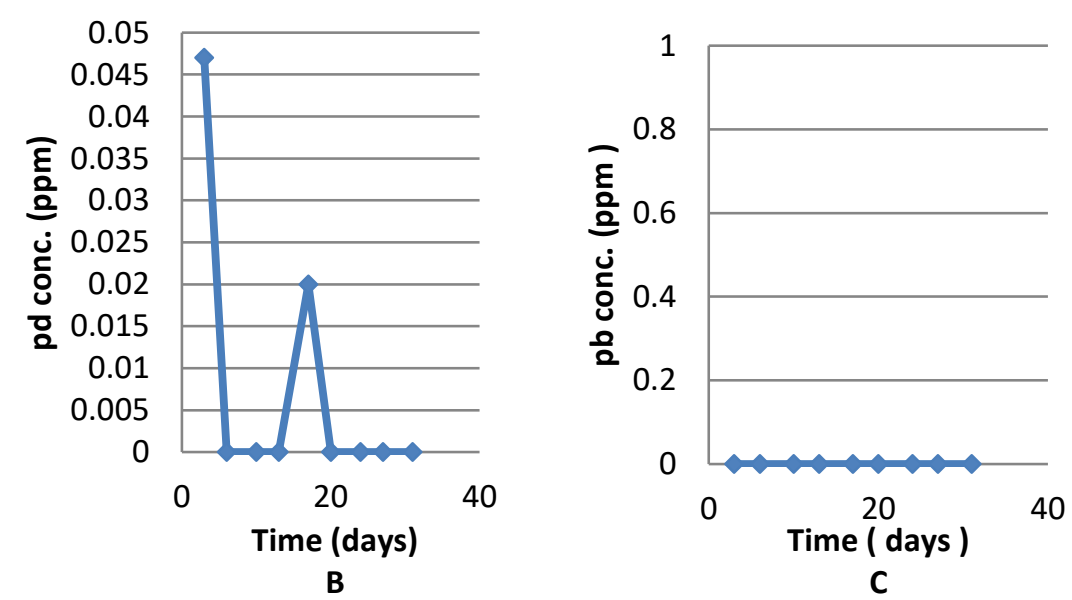

Figure 2: Variation of Lead Concentration (ppm) with time (days) at A, B, C for the month of March
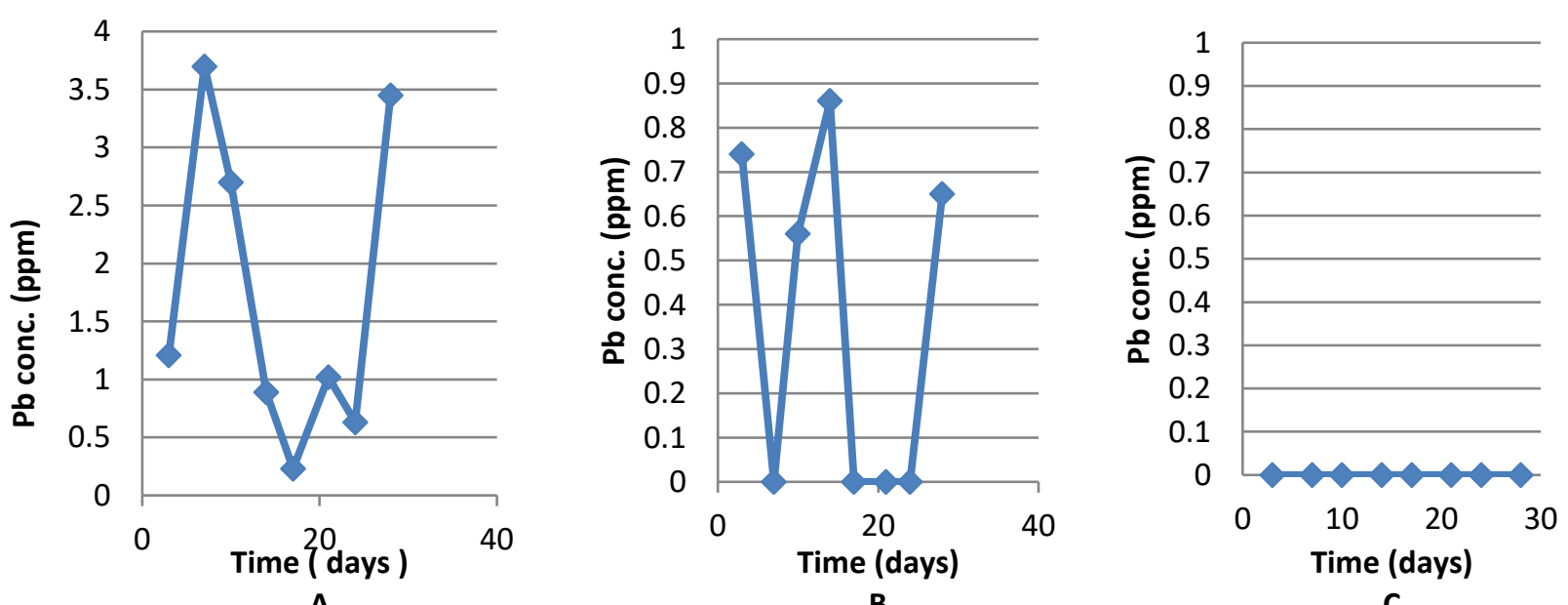

Figure 3: Variation of Lead Concentration (ppm) with time (days) at A, B, C for the month of April 


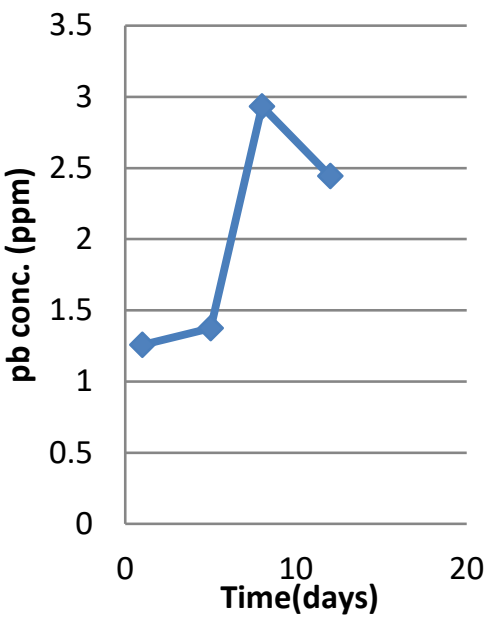

A

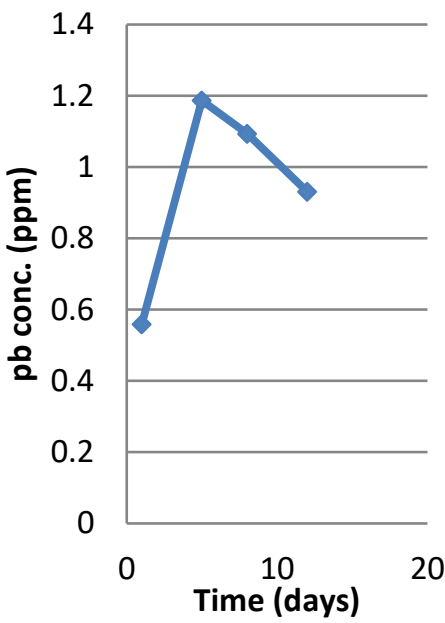

B

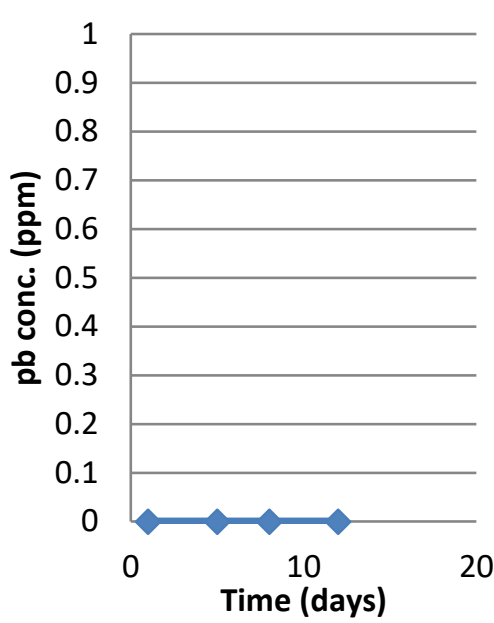

C

Figure 4: Variation of Lead Concentration (ppm) with time (days) at locations $A, B, C$ for the month of May

Table 1: Rainfall Records and Lead Concentrations at the various locations

\begin{tabular}{ccccc}
\hline \multirow{2}{*}{ Date } & $\begin{array}{c}\text { Rainfall Amount } \\
(\mathrm{mm})\end{array}$ & \multicolumn{3}{c}{ Concentration of Lead $(\mathrm{ppm})$ at locations } \\
\cline { 3 - 5 } March 1 & - & 0.792 & 0.047 & $\mathrm{C}$ \\
6 & - & 0.885 & 0 & 0 \\
10 & - & 0.163 & 0 & 0 \\
13 & - & 0.116 & 0 & 0 \\
17 & 10.41 & 0.303 & 0 & 0 \\
20 & - & 0.82 & 0.02 & 0 \\
24 & - & 0.40 & 0 & 0 \\
27 & - & 0.49 & 0 & 0 \\
31 & - & 0.232 & 0 & 0 \\
April 3 & 1.21 & 1.21 & 0.74 & 0 \\
7 & - & 3.70 & 0 & 0 \\
14 & - & 0.89 & 0.86 & 0 \\
17 & - & 0.23 & 0 & 0 \\
21 & - & 1.02 & 0 & 0 \\
24 & 11.43 & 0.63 & 0 & 0 \\
28 & - & 3.45 & 0.65 & 0 \\
May 1 & 15.49 & 1.257 & 0.559 & 0 \\
5 & - & 1.374 & 1.187 & 0 \\
8 & - & 2.933 & 1.094 & \\
12 & 31.24 & 2.444 & 0.931 & \\
\hline
\end{tabular}

\section{CONCLUSION}

The study has investigated pollutant (specifically Lead) concentrations in soil samples collected at three different locations that are exposed to various levels of vehicular traffic. Analysis of the results indicated higher level of Lead concentration at locations exposed to relatively higher levels of vehicular traffic.There is therefore a relationship between vehicular traffic and level of Lead concentration in the soils. Samples from location A had highest levels of Lead concentration ( $\max =$ 3.7ppm) followed by location $B(\max =0.86$
ppm).Significantly samples from location $C$ which is not exposed to vehicular traffic consistently had zero level of Lead concentration. Assuming absence of other main sources of pollution, the lead presence could be attributed to vehicular emission as a result of combustion of leaded fuel. The impact is higher in areas with higher vehicular activities.

The adequate recognition of the need to combat vehicular soil pollution and pollution from other nonpoint sources could be the only means to protect our environment from the threatening problem of environmental pollution. There is need for the 
establishment of comprehensive monitoring system and information gathering on pollution levels in our environment including soil.Since leaded Petrol is the major source of Lead in our environment, consumption of leaded petrol should be discouraged. There is need for adequate legal framework to ensure that only environmentally friendly vehicles are imported into the country. The policy of not importing vehicles older than 10years should be enforced.

Finally, we wish to emphasise that the assumption of vehicular emission as a source of the Lead in the soil does not foreclose the possibility of other sources of pollution. We therefore recommend further studies on the possibility of increase in levels of Lead in soils as a result of other pollution sources like oil leakages and spills from vehicles.

\section{REFERENCES}

[1] United Nations (1998). Prospect of World Urbanization. Population study no. 112, New York.

[2] Alloway, B. J. (1990). Heavy Metals in Soil. Glassgow Publications New York.

[3] Atterwell, P. (1993). Ground Pollution. E \& FN Spon Publishers. New York.

[4] Abam F. I. and Unachukwu C.O. (2009). Vehicular Emission and Industrial Air Quality in Nigeria. European Journal of Scientific Research.

[5] Fu, L. (2001). Assessment of Vehicular Pollution in China. Journal of the air and Waste Management. 51(5): 658-668.

[6] Goyal S. (2006). Understanding Urban Vehicular Pollution Problem via-a-vis ambient air quality. Case study of mega city (Delhi, India). Environmental Monitoring and Assessment. 119.557-569.
[7] Adeyanju A. A. and Monahar K (2017). Effects of Vehicular Emission on Environmental Pollution in Lagos. SCI Africa Journal of Scientific issues, Research and Essays. Vol 5 (4).p 34-51.

[8] Magbagbeola, N.O. (2001). The Use of Economic Instruments for Industrial pollution Abatement in Nigeria. Application to Lagos Lagoon. Selected Papers, Annual Conference of Nigerian Economic Society held in Port Harcourt.

[9] USEPA (1994). Synthetic Precipitation Leaching Procedure: US Environmental Protection Agency, Office of Solid Waste Sw-846 Method 1312.

www.epa.gov/epaoswer/hazard/test/main.htm . Accessed June 12, 2018.

[10] ASTDR (1988). The Nature and extent of lead poisoning in children in the United States. A Report to Congress. Agency for Toxic substances and Disease Registry.

[11] Popescu, C.G. (2011). Relation between vehicle traffic and heavy metals from the particulate matters. Romanian Reports in Physics. vol. 25(2) p 141-148.

[12] Landrigan, P, Gehlabach, S., Rosenblum, B., Scholts, J., Candelaria, R., Barthel, W., Liddle, J., Smrek, A., Staehling, N.S. (1975). Lead absorption near an Ore Smelter; The Role of particulate Lead New Engl. J. Med vol 292 p. (123-129).

[13] Needleman, H. L., Schell, A., Bellinger, D., Leviton, A., Alfred, E.N. (1990). The long-term effects of exposure to low doses of Lead in childhood. An 11 year follow-up report. New Engl. J. Med vol 332 p. (83-88).

[14] Google map Data. (2018). Map of Nsukka www.google.com/map. Accessed December28,2018. 